\title{
Ultrasonographic assessment of splenic volume at presentation and after anti-malarial therapy in children with malarial anaemia
}

\author{
Moses Laman ${ }^{1,2}$, Susan Aipit ${ }^{2}$, Cathy Bona ${ }^{2}$, Peter M. Siba ${ }^{2,3}$, Leanne J. Robinson ${ }^{2,4,5}$, Laurens Manning ${ }^{1+}$ \\ and Timothy M. E. Davis ${ }^{1 *+}$
}

\begin{abstract}
Background: Splenic enlargement is a component of the host response to malaria and may also influence the genesis and progression of malarial anaemia. Few cross-sectional and no longitudinal studies have assessed the relationship between splenic volume measured ultrasonographically and haemoglobin concentrations in children with malaria.

Methods: Fifteen Papua New Guinean children with severe malarial anaemia (SMA; haemoglobin $<50 \mathrm{~g} / \mathrm{L}$ ) and ten with moderate malarial anaemia (MMA; $51-99 \mathrm{~g} / \mathrm{L}$ ) were recruited. The SMA patients were given intramuscular artemether followed by oral artemisinin combination therapy (ACT), and were transfused one unit of packed cells 0.3-4.0 days post-admission. The MMA patients were treated with ACT. Splenic enlargement (Hackett's grade, subcostal distance and ultrasonographically determined volume) and haemoglobin concentrations were measured on days $0,1,2,3,7,14,28$, and 42.

Results: Associations between Hackett's grade, subcostal distance and splenic volume were modest $\left(r_{s} \leq 0.62\right.$, $P<0.001)$. Baseline splenic volume was not associated with age or haemoglobin $(P \geq 0.90)$. Mean splenic volume had fallen by approximately $50 \%$ at day 14 in children with MMA ( $P \leq 0.011$ vs days 0,1 and 2 ), but there was no change in the SMA group $(P \geq 0.30)$. There was no change in haemoglobin in the MMA group during follow-up but a rise in the SMA group to day 7 ( $P \leq 0.05$ vs days $0,1,2$, and 3 ) which paralleled the packed cell volume transfused.

Conclusions: Clinical assessment of splenomegaly is imprecise compared with ultrasonography. Serial splenic volumes and haemoglobin concentrations suggest that the spleen does not influence post-treatment haemoglobin, including after transfusion.
\end{abstract}

Keywords: Malaria, Plasmodium falciparum, Anaemia, Splenic volume, Children

\section{Background}

Splenomegaly is one of the oldest known clinical manifestations of malaria, having been recognized before the discovery of the Plasmodium parasite [1]. Spleen size is conventionally graded according to Hackett's system [2] with a score ranging from zero (no palpable spleen) to five (massive enlargement extending towards the umbilicus; see Fig. 1), but the vertical distance in centimetres $(\mathrm{cm})$

\footnotetext{
*Correspondence: tim.davis@uwa.edu.au

${ }^{\dagger}$ Equal contributors

'School of Medicine and Pharmacology, University of Western Australia,

Fremantle Hospital, PO Box 480, Fremantle 6959, WA, Australia

Full list of author information is available at the end of the article
}

from the lower costal margin in the mid-clavicular line has also been used in studies of malaria [3]. The rate of palpable splenomegaly can provide an indication of the intensity of malaria transmission in endemic areas when blood smears are unavailable $[2,4]$.

In patients with malaria, clearance of both parasitized and non-parasitized red blood cells results in splenic enlargement $[5,6]$ which in turn contributes, along with intravascular haemolysis and dyserythropoiesis, to anaemia [7-10]. Animal studies also show the pathophysiological importance of splenic enlargement, with explanted and post-mortem spleen sizes associated with the severity of anaemia complicating malaria $[11,12]$. The spleen is also 


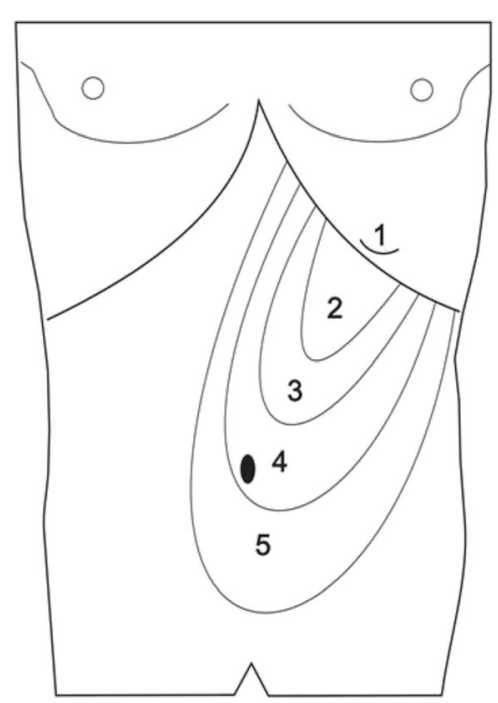

Grade 0: Normal, impalpable spleen

Grade 1: Spleen palpable only on deep inspiration

Grade 2: Spleen palpable on mid clavicular line, half way between umbilicus and costal margin

Grade 3: The spleen expands towards the umbilicus

Grade 4: The spleen goes past the umbilicus

Grade 5: The spleen expands towards the symphisis pubis

Fig. 1 Hackett's grading system for palpable splenomegaly

an important site for pathogen-specific adaptive and maladaptive $\mathrm{T}$ and $\mathrm{B}$ cell immune responses. At its most extreme, aberrant $\mathrm{T}$-cell immune regulation of effective humoral responses can lead to the massive splenic enlargement seen in hyper-reactive splenomegaly syndrome, a major public health problem in some populations which is associated with significantly increased mortality.

The complex three-dimensional shape of the spleen and its position in the left upper quadrant of the abdomen complicate accurate assessment of splenic volume. Since Hackett's grading or simple uniaxial measurement may have insufficient sensitivity, ultrasonography has been used as a more accurate alternative to clinical assessment in parasitic diseases such as schistosomiasis [13]. In the case of malaria, one small paediatric study showed that spleen size by palpation significantly overestimated the true incidence of splenomegaly as measured by ultrasound [14]. Another study involving largely adults questioned the value of splenic ultrasound as an aid to diagnosis and did not find that ultrasonographically detected splenic enlargement was associated with indices of severity [15]. By contrast, children with severe malaria anaemia (SMA; haemoglobin concentration $<50 \mathrm{~g} / \mathrm{L}$ ) in a second crosssectional paediatric study had higher splenic volumes adjusted for total body surface area than those with cerebral malaria, and a low splenic volume was associated with subsequent mortality [16]. There have, however, been no studies that have compared serial changes in splenic volume after treatment assessed by ultrasound to both simpler clinical measurements of spleen size and related outcomes such as the development of malarial anaemia. The spleen generally regresses in size within days to weeks after anti-malarial treatment [17], but blood transfusion as part of the management of SMA may promote persistent splenic enlargement which could, in turn, attenuate the benefits of transfusion [18].

In malaria-endemic areas of Papua New Guinea (PNG), malarial anaemia associated with splenomegaly is a common clinical presentation. Despite a declining incidence of malaria, $13 \%$ of healthy asymptomatic PNG children have splenomegaly [19], while anaemia, including SMA, is common and multifactorial [20]. The aim of the present study was to i) compare the traditional methods of splenic size assessment with ultrasonographic volumetric measurement; and, ii) evaluate serial changes in spleen size and their haematological consequences in children with SMA and moderate malarial anaemia (MMA).

\section{Methods}

\section{Study sites, patients and approvals}

Children with SMA were enrolled between March 2009 and May 2010 as participants in a prospective observational study of severe paediatric illnesses that was conducted at Modilon Hospital on the north coast of mainland PNG. The clinical and laboratory characteristics of these patients have been described previously [20]. In brief, they were aged one to ten years and had Plasmodium falciparum and/or Plasmodium vivax on light microscopy of a peripheral blood smear together with severe anaemia. Standardized case report forms containing demographic and clinical information were completed by trained research nurses. Clinical management, including blood transfusions, were in accordance with World Health Organization (WHO) [21] and PNG national guidelines [22]. Intramuscular artemether was given at an initial dose of $3.2 \mathrm{mg} / \mathrm{kg}$ of body weight, followed by daily doses of at least $1.6 \mathrm{mg} / \mathrm{kg}$ until oral artemisinin combination therapy (ACT) could be tolerated. Daily clinical assessments were 
performed in hospital. Home visits were conducted at prespecified time-points after discharge.

Children with MMA (haemoglobin 51-99 g/L) were recruited at Mugil Health Centre located approximately $50 \mathrm{~km}$ from the township of Madang between April 2011 and June 2012. Screening for MMA was either part of assessment for eligibility in a randomized trial of $\mathrm{ACT}$ if the children were aged $<$ five years [23] (none of the present children met the inclusion criteria for the clinical trial) or it was performed during routine assessment of older children presenting with fever. Inclusion criteria for the present study were i) age between one and ten years; ii) $P$. falciparum and/or $P$. vivax on peripheral blood smear; and, iii) no clinical or laboratory evidence of severe malaria or another infection. All children with MMA were treated with ACT (artemether-lumefantrine) in accordance with the PNG standard treatment guidelines [22].

The study was approved by the PNG Institute of Medical Research Institutional Review Board and the Medical Research Advisory Committee of the PNG National Health Department (MRAC No. 11.07). Written informed consent was obtained from a parent or guardian of each study participant.

\section{Clinical and laboratory procedures}

All children were assessed on days $0,1,2,3,7,14,28$, and 42. At baseline, $500 \mu \mathrm{L}$ venous blood was collected into Microtainer ${ }^{\circ}$ tubes (Becton Dickenson, Franklin Lakes, USA) containing $0.39 \mathrm{mg}$ disodium edetate and a full blood count was performed using a Coulter counter (ACT3 diff PAK, Beckman Coulter, Brea, USA). At each subsequent follow-up visit, $250 \mu \mathrm{L}$ blood was collected by finger prick for Coulter counter haemoglobin measurement and malaria microscopy. In children with SMA, an additional 1-3 $\mathrm{mL}$ of blood was collected for bacterial culture in Bactec $^{\mathrm{TM}}$ Peds Plus ${ }^{\mathrm{TM}} / \mathrm{F}$ bottles (Becton Dickinson) and incubated using an automated Bactec ${ }^{\mathrm{TM}}$ system. For malaria microscopy, standard procedures were used [24, 25]. Giemsa-stained thick blood smears were examined and parasitaemia quantified independently by two skilled microscopists, with discrepancies adjudicated by a senior microscopist.

Splenic size was assessed by palpation at each visit with children in the supine position. Hackett's grading was determined in each case (see Fig. 1) and a tape measure was used to determine the distance in $\mathrm{cm}$ from the lower costal margin to the tip of the spleen in the mid-axillary line. Ultrasonography in each SMA and MMA patient and at each time point was performed using a MicroMaxx Ultrasound System (SonoSite, Brookvale, New South Wales, Australia) by the study clinician (ML) or one of two trained nursing officers (SA and $\mathrm{CB}$ ) with the patient in the right recumbent position. These study staff were all blind to the results of prior splenic volume assessments and were not allocated systematically to individual patients or time points. The spleen length (L), width (W) and depth (D) were assessed using with the probe in the longitudinal axis (L) and transverse axis (W and D; see Fig. 2). With parental assistance, valid images in each dimension were obtained from the majority of children at each time-point. Splenic volume in $\mathrm{cm}^{3}$ was calculated from the formula $0.524 \times \mathrm{L}(\mathrm{cm}) \times \mathrm{W}(\mathrm{cm}) \times \mathrm{D}$ $(\mathrm{cm})$ where $\mathrm{L}, \mathrm{W}$ and $\mathrm{D}$ were obtained from the best single image recorded $[26,27]$. The within- and betweenoperator variability in splenic volume has proved to be acceptably low in other clinical contexts, including studies involving children and those using a portable ultrasound machine [28-31].

\section{Data analysis}

The computer package IBM SPSS Statistics 20 (IBM Corporation, Somers, NY, USA) was used for statistical analysis. Data are summarized as mean \pm SD or median (inter-quartile range). Two-sample comparisons were by Mann-Whitney $U$-test for continuous data and by Fisher's exact test for proportions. Bivariate associations between variables were assessed using Spearman rank correlation co-efficient $\left(\mathrm{r}_{\mathrm{s}}\right)$. For serial splenic volume and haemoglobin data, missing data were imputed up to a maximum of two values per patient using linear interpolation or last observation carried forward. Differences between groups at each time-point were assessed using generalized linear mixed-effect models with gamma regression (given the skewed nature of the splenic volume data) and Bonferroni correction for pair-wise comparisons. A two-tailed significance level of $P<0.05$ was used throughout.

\section{Results}

\section{Baseline patient characteristics}

Ten children with MMA and 15 with SMA were recruited. Their baseline characteristics are summarized in Table 1 . All had P. falciparum mono-infections by expert microscopy at the time of enrolment, consistent with the greater transmission, and stronger association with anaemia, of $P$. falciparum vs $P$. vivax in the study area [20,24]. Children with SMA were significantly younger than those with MMA, and they had a higher pulse rate, total white blood cell count and platelet count. At baseline, splenic volumes measured by ultrasound ranged from $14 \mathrm{~cm}^{3}$ to $265 \mathrm{~cm}^{3}$. There was no significant difference between the two patient groups in splenic volume, length below the left costal margin or Hackett's grade $(P \geq 0.50$; see Table 1). Baseline splenic volume was not associated with haemoglobin concentration $\left(r_{s}=0.02\right.$; see Fig. 3$)$ or age $\left(\mathrm{r}_{\mathrm{s}}=-0.03 ; P \geq 0.90\right.$ in each case $)$. 


\section{Panel A}
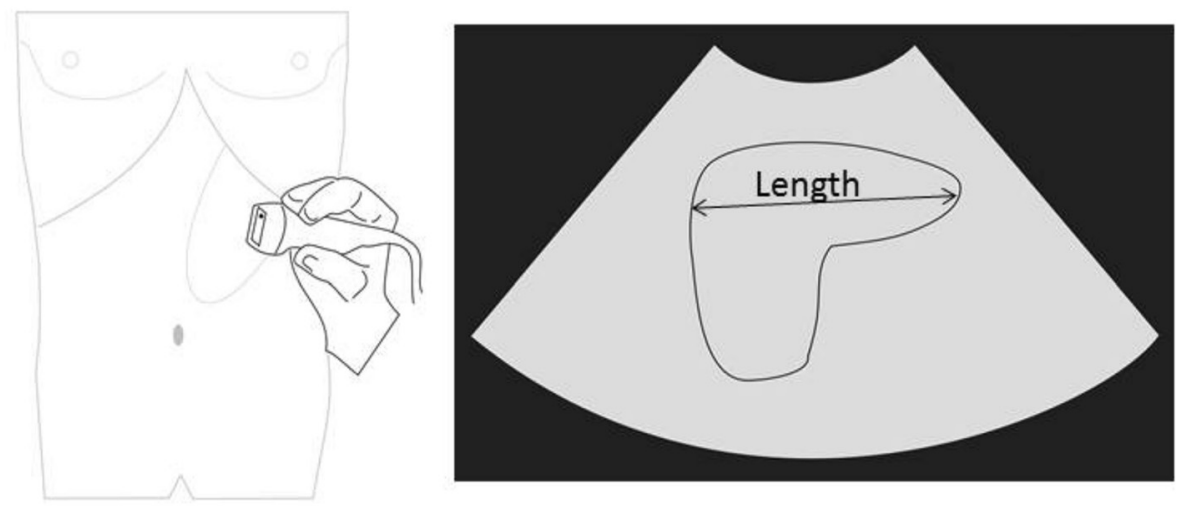

\section{Panel B}
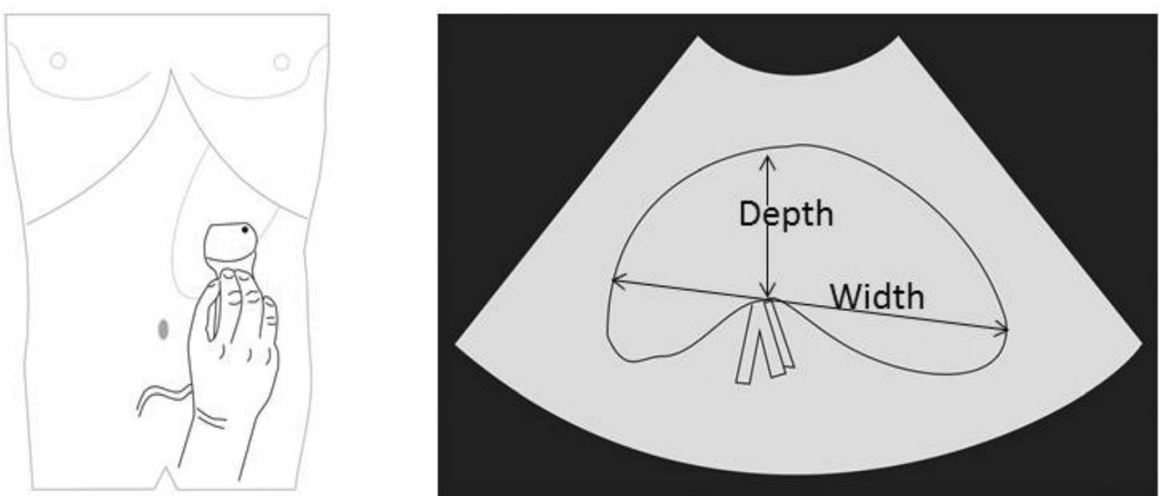

Fig. 2 Assessment of splenic volume using ultrasonography. Panel a illustrates measurement of spleen length in the longitudinal view. Panel b shows measurement of width and thickness on the transverse view

\section{Clinical course}

There was a rapid clearance of $P$. falciparum parasitaemia in all children with MMA. Nine (90 \%) were slide negative within $24 \mathrm{~h}$ and all were slide negative by day 3 . However, gametocyte carriage persisted up to 14 days in two children (20\%) and up to 28 days in one child (10\%). None of the children with MMA required transfusion, and all were discharged from hospital when they were afebrile and aparasitaemic.

All children with SMA were blood slide negative for malaria within $24 \mathrm{~h}$. Gametocyte carriage persisted up to 28 days in one child. Blood cultures performed in children with SMA were negative for bacterial pathogens in all cases. All children with SMA were transfused one unit of packed cells $(300 \mathrm{~mL})$ within four days of admission (median 2.5 (range 0.3-4.0) days). There were no deaths during follow-up in the SMA group.

\section{Associations between splenic volume and clinical assessment of splenic enlargement}

To assess correlations between the traditional methods of assessing splenic enlargement (distance below the left costal margin and Hackett's grade), combined measurements from all children were obtained at all time-points. Both the distance below the left costal margin and Hackett's grade were significantly associated with splenic volume measured by ultrasound $\left(r_{\mathrm{s}}=0.62\right.$ and 0.59 , respectively, $P<0.001$ in each case; see Fig. 4). However, there was marked variation in both cases with, for example, up to a ten-fold variation in splenic volume at each Hackett's grade. In those children without palpable splenomegaly, the range of splenic volumes determined by ultrasound $\left(<110 \mathrm{~cm}^{3}\right.$; see Fig. 4) was consistent with mean values for normal children aged between one year $\left(42 \mathrm{~cm}^{3}\right)$ and ten years $\left(108 \mathrm{~cm}^{3}\right)$ as assessed by computed tomography [32].

\section{Post-treatment changes in splenic volume and haemoglobin}

These were assessable in ten children with MMA and 12 with SMA with complete (including imputed) data to day 14. In children with MMA, mean splenic volume did not change initially but then fell after day 2 to approximately half the admission value at day $14(P \leq 0.011 v s$ days 0,1 and 2; see Fig. 5). There was no equivalent change in the two weeks after treatment in the SMA group despite 
Table 1 Baseline clinical and haematology data in children with moderate and severe malarial anaemia

\begin{tabular}{|c|c|c|c|}
\hline & $\begin{array}{l}\text { Moderate malarial anaemia } \\
(n=10)\end{array}$ & $\begin{array}{l}\text { Severe malarial anaemia } \\
(n=15)\end{array}$ & $\begin{array}{l}P- \\
\text { value }\end{array}$ \\
\hline Age (months) & $74(58-87)$ & $36(32-49)$ & 0.001 \\
\hline Male sex (\%) & 50 & 40 & 0.47 \\
\hline Axillary temperature $\left({ }^{\circ} \mathrm{C}\right)$ & $37.1(36.3-38.6)$ & $37.6(36.6-38.0)$ & 0.75 \\
\hline Pulse rate (beats/min) & $97(80-120)$ & $128(109-135)$ & 0.003 \\
\hline Respiratory rate (breaths/min) & $28(23-33)$ & $28(28-39)$ & 0.14 \\
\hline Blantyre Coma Score $\leq 4(\%)$ & 0 & 20 & 0.20 \\
\hline Palpable spleen size (cm) & $5.5(3.7-7.0)$ & $4(2.0-7.9)$ & 0.50 \\
\hline Hackett's grade & $2.5(2-3)$ & $3.0(1.0-4.0)$ & 0.93 \\
\hline Splenic volume $\left(\mathrm{cm}^{3}\right)$ & $84(49-102)$ & $54(36-149)^{a}$ & 0.66 \\
\hline Total White cell count $\left(10^{9} / \mathrm{L}\right)$ & $6.5(3.1-9.1)$ & $9.5(6.5-18.8)$ & 0.032 \\
\hline Lymphocytes (\%) & $46(32-56)$ & $40(21-57)$ & 0.42 \\
\hline Monocytes (\%) & $11(7-18)$ & $9.6(6-12)$ & 0.32 \\
\hline Granulocytes (\%) & $46(32-53)$ & $51(32-72)$ & 0.30 \\
\hline Total platelet count $\left(10^{9} / \mathrm{L}\right)$ & $108(50-221)$ & $126(43-211)$ & $<0.001$ \\
\hline Haemoglobin (g/L) & $77(67-87)$ & $46(39-49)$ & $<0.001$ \\
\hline Red blood cell count $\left(10^{12} / L\right)$ & $2.7(2.3-3.6)$ & $2.2(1.3-4.4)$ & 0.42 \\
\hline Haematocrit (\%) & 22 18-26) & $16(10-25)$ & 0.13 \\
\hline Mean cell volume (fL) & $66(62-77)$ & $63(55-83)$ & 0.56 \\
\hline Mean cell haemoglobin (pg) & $20(19-24)$ & $22(19-27)$ & 0.25 \\
\hline Mean cell haemoglobin concentration (g/L) & $310(284-324)$ & $339(308-380)$ & 0.024 \\
\hline Red cell distribution width & $17.5(14.2-21.0)$ & $19.1(15.3-30.1)$ & 0.42 \\
\hline P. falciparum density $(/ \mu \mathrm{L})$ & $5776(235-33,569)$ & $600(190-3388)$ & 0.37 \\
\hline
\end{tabular}

${ }^{\mathrm{a}}$ Two children in the SMA group did not have a valid splenic volume measurement

Data are medians (interquartile range) or percentages

transfusion at around day $2(P \geq 0.30$ for pair-wise comparisons between time-points to day 14). The mean splenic volume at day 7 was significantly higher than that in the MMA group at that time $(P=0.043)$. By day 14 , there was no significant difference in splenic volume between the two groups of children, a situation that was also observed at days 28 and $42(P>0.22)$.

There was no significant change in haemoglobin concentration in the two weeks after treatment in the MMA group ( $P \geq 0.10$ for pair-wise comparisons between time-points to day 14; see Fig. 5). There was, however, a significant rise in the relatively low haemoglobin concentrations in the SMA group after day 3 ( $P \leq 0.05$ for day 7 haemoglobin $v s$ days 0 , 1, 2 and 3; see Fig. 5), so that levels in the SMA group were higher than those in the MMA group at day $7(P=0.022)$. By day 14, there was no significant difference in haemoglobin between the two groups of children, a situation that was also observed at days 28 and $42(P>0.38)$.

\section{Discussion}

The present study demonstrates that splenic volume determined by ultrasound in children presenting with falciparum malaria in a hyperendemic area of coastal PNG is variable and not associated with the degree of anaemia at presentation. Simple clinical measures of splenic enlargement (uniaxial splenic length below the costal margin and Hackett's grading) were only moderately associated with splenic volume in this patient group, consistent with the relatively low sensitivity and specificity of palpation compared with ultrasonography in ascertaining the presence and degree of splenomegaly regardless of the underlying cause [33]. The temporal changes in splenic volume after anti-malarial treatment differed by anaemia status. In SMA patients, blood transfusion given during the first four days of treatment was associated with a stable mean splenic volume over the first two weeks after treatment in the presence of a progressive rise in haemoglobin to day 7. By contrast, splenic volume decreased over the first two weeks after treatment in the MMA group without a significant change in haemoglobin. These observations suggest that transfusion attenuates resolution of malaria-associated splenomegaly but also that the spleen does not sequester a significant volume of transfused blood in children with malaria and severe anaemia. 


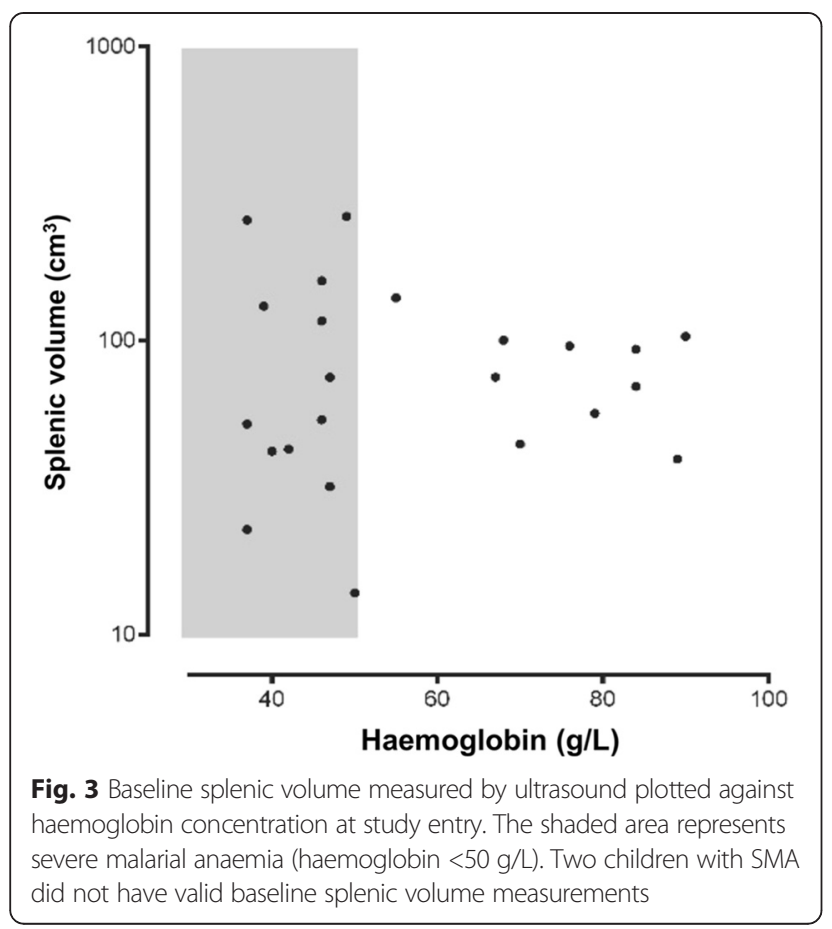

Given malaria endemicity in the study area [34], the risk of other infections [35] and haemoglobinopathies such as Southeast Asian ovalocytosis which are relatively common in PNG [36], it is not surprising that most of the present children had a degree of splenomegaly when recruited and that this was not associated with features such as age and haemoglobin. Nevertheless, palpation with or without linear measurement of spleen size may be adequate for clinical studies and epidemiological surveys in which detection of splenic enlargement is important [2-4], as long as its limitations are acknowledged. Palpation for splenomegaly has a sensitivity of between 28 and $77 \%$, and a specificity of between 62 and $99 \%$, in comparison with diagnostic imaging modalities [33]. The greater specificity vs sensitivity is consistent with the fact that Hackett's grade 0 was consistently associated with a normal splenic volume by ultrasound $\left(<108 \mathrm{~cm}^{3}\right)$ [32] in the present study. Ultrasonography represents a low-cost, non-invasive and accurate technique for repeated assessment of splenic volume [28-31, 33]. In the present study, novel ultrasonographic data were collected relating to temporal changes in this variable, which would not have been possible using simple clinical assessments.

The most interesting observations in the present study related to the relationship between serial ultrasonographic splenic volume estimates and haemoglobin concentrations after anti-malarial treatment. Reticuloendothelial clearance of parasitized and non-parasitized erythrocytes [7, 37] as well as acutely depressed erythropoiesis [10] can result in an initial temporary post-treatment reduction in haemoglobin [38]. This can be partially offset by splenic 'pitting, a process which is strongly related to artemisinin treatment
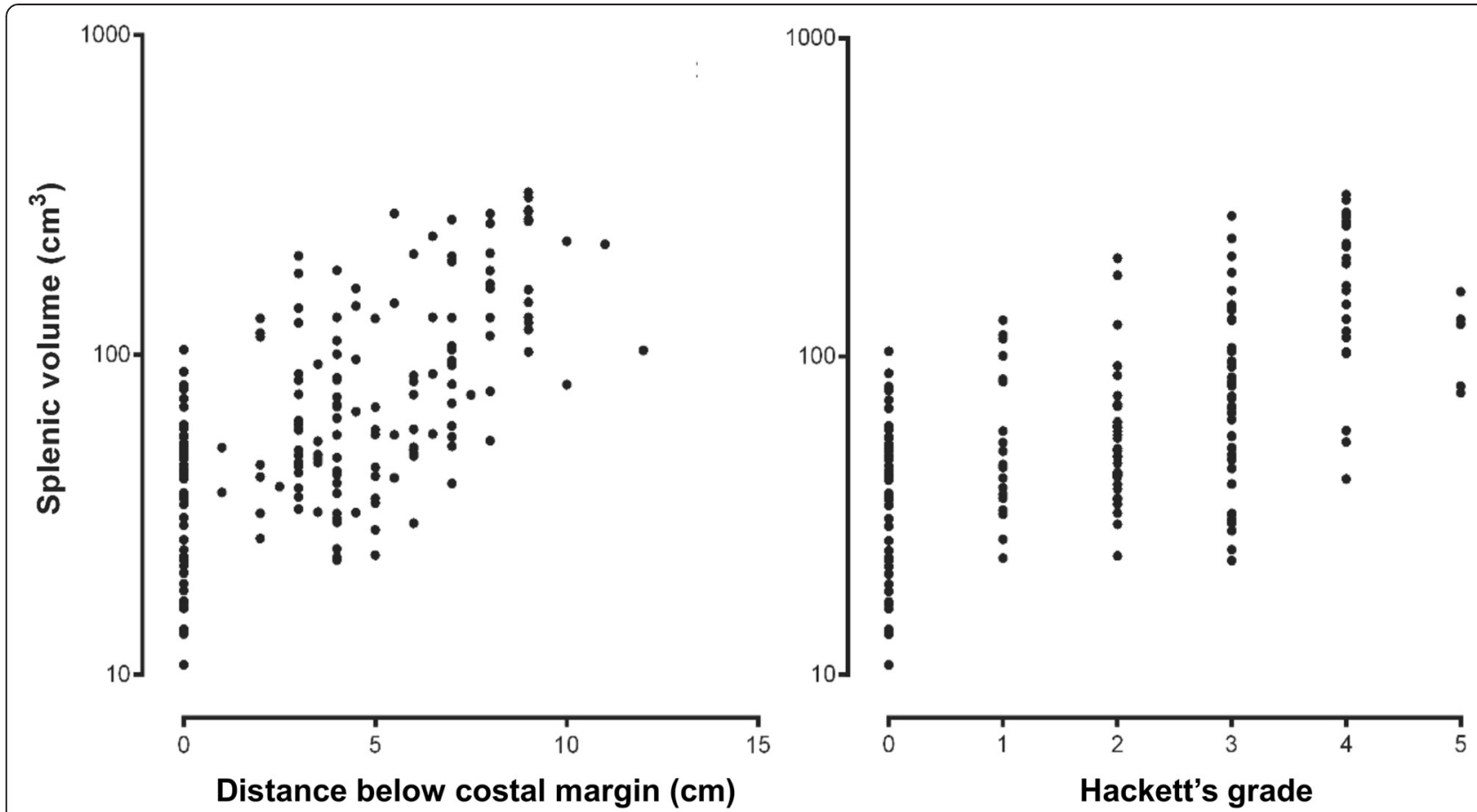

Fig. 4 Splenic volume by ultrasound plotted on a logarithmic scale against longitudinal distance in cm below the costal margin (left) and Hackett's grade (right) in children with moderate or severe malarial anaemia 

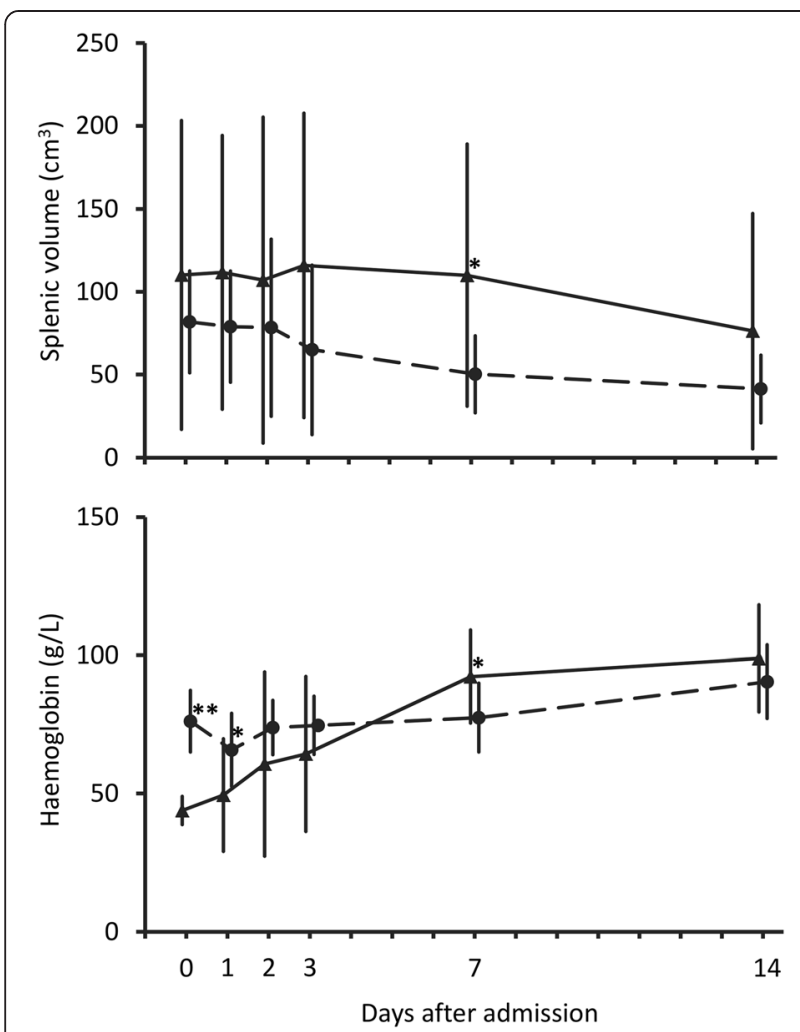

Fig. 5 Serial changes in splenic volume (upper panel) and haemoglobin (lower panel) in children with MMA $\bullet--\bullet)$ compared to those with SMA who were transfused $(\boldsymbol{\Delta}--\mathbf{\Delta})$ Data points are means and SDs (vertical bars). ${ }^{*} P<0.05$ and ${ }^{*} P<0.001$ for between group comparison using generalized linear mixed-effects models

and immune status [39] and which removes parasites from infected erythrocytes and returns these once infected cells to the circulation. In children with MMA in the present study, the initial fall in haemoglobin was not significant and splenic volume did not change during the first few days after anti-malarial treatment had been started. The later significant reduction in splenic volume was not associated with changes in haemoglobin in this group.

By contrast, the mean haemoglobin concentration in the SMA group increased between day 0 and day 7, reflecting transfusions given during the first four days [10]. A number of children with SMA had large spleens at baseline $\left(>100 \mathrm{~cm}^{3}\right.$ in one third). It has been shown that splenomegaly attenuates the efficacy of blood transfusion through splenic sequestration of erythrocytes [18], but this did not appear to be present in the present children since splenic volume did not increase significantly between days 0 and 3, and the rise in haemoglobin (mean change $48 \mathrm{~g} / \mathrm{L}$ between days 0 and 7) was consistent with the volume of blood transfused (expected change $52 \mathrm{~g} / \mathrm{L}$ for a 12-kg child receiving $300 \mathrm{~mL}$ packed cells [40]). However, there was also no reduction in splenic volume by day 7 post-treatment as was seen in the MMA group. This suggests that transfusion attenuates the resolution of malaria-associated splenomegaly, perhaps through mild or subclinical immune activation resulting from red cell incompatibility [41]. Alternatively, the children with SMA had a larger sequestered biomass of parasitized erythrocytes than those with MMA, which also contributed to persistent splenomegaly through host immune responses [42].

The present study had limitations. Determination of within- (intra-day and inter-day) and between-observer variation in ultrasonographic splenic measurements were considered but would have been difficult in a high-turnover paediatric ward and as part of home follow-up visits in the rural tropics. The number of trained operators both performing ultrasounds and assessing splenic size clinically was, however, restricted to limit measurement variability. There were relatively small numbers of children in each group but data collection over the six-week follow-up period was complete in most patients. A larger sample may have allowed an assessment of whether the inverse relationship between splenic volume and mortality found in an African paediatric study [16] is also a feature in PNG children but, consistent with the favourable outcome in all the present patients, the case fatality rate associated with severe malaria in Melanesian populations is relatively low [43].

\section{Conclusions}

The present study demonstrates that ultrasonographic studies are feasible using a portable system in logistically challenging research environments. The recognized limitations of clinical assessment of splenic size were confirmed by the present data. Serial splenic volume measurements and simultaneous haemoglobin concentrations suggest that the spleen does not have a major role in determining changes in post-treatment haemoglobin, including in transfused patients with SMA.

\section{Abbreviations}

ACT: Artemisinin combination therapy; D: Depth; L: Length; MMA: Moderate malarial anaemia; PNG: Papua New Guinea; $r_{s}$ : Spearman rank correlation co-efficient; SMA: Severe malarial anaemia; W: Width; WHO: World Health Organization.

\section{Competing interests}

The authors declare that they have no competing interests.

\section{Authors' contributions}

TMED and LM designed the study. ML, SA and CB collected the data under the supervision of $L M$ and with logistic and administrative support from $L R$ and PS. LM, ML and TMED analysed the data. ML and LM drafted the manuscript, the final version of which was prepared by TMED after input from all authors. All authors read and approved the final manuscript. 


\section{Acknowledgements}

The authors gratefully acknowledge support from staff from the Modilon Hospital Paediatrics Ward, the Mugil Health Centre and the Vector Borne Diseases Unit of the Papua New Guinea Institute of Medical Research. We also thank Steven Fraser and Michelle Bavcevic for assistance with preparation of Figures and Wendy Davis for statistical advice. The children with SMA were recruited as part of a severe childhood illness study funded by a National Health and Medical Research Council (NHMRC) grant (\#513782) while those with MMA were recruited as part of screening for an anti-malarial intervention trial also funded by NHMRC (\#634343). ML was supported by a Fogarty Foundation scholarship and an Australian PhD Scholarship Award, LM by a Basser Award from the Royal Australasian College of Physicians and a postgraduate NHMRC scholarship, and TMED by an NHMRC Practitioner Fellowship.

\section{Author details}

${ }^{1}$ School of Medicine and Pharmacology, University of Western Australia, Fremantle Hospital, PO Box 480, Fremantle 6959, WA, Australia. ${ }^{2}$ Papua New Guinea Institute of Medical Research, Madang, Papua New Guinea. ${ }^{3}$ Department of Microbiology, Division of Veterinary and Biomedical Sciences, James Cook University, Townsville, Australia. ${ }^{4}$ Infection and Immunity Division, Walter and Eliza Hall Institute, Parkville, VIC, Australia. ${ }^{5}$ Department of Medical Biology, University of Melbourne, Melbourne, VIC, Australia.

\section{Received: 12 March 2015 Accepted: 20 May 2015}

\section{Published online: 28 May 2015}

\section{References}

1. Shukla M, Singh N, Singh MP. Spleen rates and infant parasite rates as surveillance tool for malaria control in remote hard to reach areas of central India. Malar J. 2011;10:381.

2. Baird JK, Bangs MJ, Maguire JD, Barcus MJ. Epidemiological measures of risk of malaria. Methods Mol Med. 2002;72:13-22.

3. Helegbe GK, Goka BQ, Kurtzhals JA, Addae MM, Ollaga E, Tetteh JK, et al. Complement activation in Ghanaian children with severe Plasmodium falciparum malaria. Malar J. 2007;6:165.

4. Snow RW, Omumbo JA, Lowe B, Molyneux CS, Obiero JO, Palmer A, et al. Relation between severe malaria morbidity in children and level of Plasmodium falciparum transmission in Africa. Lancet. 1997:349:1650-4.

5. Jakeman GN, Saul A, Hogarth WL, Collins WE. Anaemia of acute malaria infections in non-immune patients primarily results from destruction of uninfected erythrocytes. Parasitology. 1999;119:127-33.

6. White NJ, Ho M. The pathophysiology of malaria. Adv Parasitol. 1992;31:83-173.

7. Looareesuwan S, Davis TM, Pukrittayakamee S, Supanaranond W, Desakorn V, Silamut K, et al. Erythrocyte survival in severe falciparum malaria. Acta Trop. 1991;48:263-70.

8. Looareesuwan S, Merry AH, Phillips RE, Pleehachinda R, Wattanagoon Y, Ho M, et al. Reduced erythrocyte survival following clearance of malarial parasitaemia in Thai patients. Br J Haematol. 1987;67:473-8.

9. Phillips RE, Looareesuwan S, Warrell DA, Lee SH, Karbwang J, Warrell MJ, et al. The importance of anaemia in cerebral and uncomplicated falciparum malaria: role of complications, dyserythropoiesis and iron sequestration. Q J Med. 1986:58:305-23.

10. Phillips RE, Pasvol G. Anaemia of Plasmodium falciparum malaria. Baillieres Clin Haematol. 1992:5:315-30.

11. Egan AF, Fabucci ME, Saul A, Kaslow DC, Miller LH. Aotus New World monkeys: model for studying malaria-induced anemia. Blood. 2002;99:3863-6.

12. Evans KJ, Hansen DS, van Rooijen N, Buckingham LA, Schofield L. Severe malarial anemia of low parasite burden in rodent models results from accelerated clearance of uninfected erythrocytes. Blood. 2006;107:1192-9.

13. Richter J, Domingues AL, Barata CH, Prata AR, Lambertucci JR. Report of the second satellite symposium on ultrasound in schistosomiasis. Mem Inst Oswaldo Cruz. 2001;96(Suppl):151-6.

14. Murphy S, Cserti-Gazdewich C, Dhabangi A, Musoke C, Nabukeera-Barungi N, Price D, et al. Ultrasound findings in Plasmodium falciparum malaria: a pilot study. Pediatr Crit Care Med. 2011;12:e58-63.

15. Richter J, de Bernardis C, Sagir A, Walter S, Savalli E, Haussinger D. Is ultrasound a useful adjunct for assessing malaria patients? Parasitol Res. 2004;94:349-53.
16. Kotlyar S, Nteziyaremye J, Olupot-Olupot P, Akech SO, Moore CL, Maitland K. Spleen volume and clinical disease manifestations of severe Plasmodium falciparum malaria in African children. Trans R Soc Trop Med Hyg. 2014;108:283-9.

17. Zingman BS, Viner BL. Splenic complications in malaria: case report and review. Clin Infect Dis. 1993;16:223-32.

18. Huber H, Lewis SM, Szur L. The influence of anaemia, polycythaemia and splenomegaly on the relationship between venous haematocrit and red-cell volume. Br J Haematol. 1964;10:567-75.

19. Manning L, Laman M, Townsend MA, Chubb SP, Siba PM, Mueller I, et al. Reference intervals for common laboratory tests in Melanesian children. Am J Trop Med Hyg. 2011:85:50-4.

20. Manning L, Laman M, Rosanas-Urgell A, Michon P, Aipit S, Bona C, et al. Severe anemia in Papua New Guinean children from a malaria-endemic area: a case-control etiologic study. PLoS Negl Trop Dis. 2012;6, e1972.

21. Severe falciparum malaria. Trans R Soc Trop Med Hyg. 2000:94:S1-90.

22. Paediatrics Society of PNG. Standard Treatment for Common IIInesses of Children in PNG. 2005.

23. Laman M, Moore BR, Benjamin JM, Yadi G, Bona C, Warrel J, et al. Artemisinin-naphthoquine versus artemether-lumefantrine for uncomplicated malaria in Papua New Guinean children: An open-label randomized trial. PLoS Med. 2014;11, e1001773.

24. Manning L, Laman M, Law I, Bona C, Aipit S, Teine D, et al. Features and prognosis of severe malaria caused by Plasmodium falciparum. Plasmodium vivax and mixed Plasmodium species in Papua New Guinean children. PLoS One. 2011;6, e29203.

25. Laman M, Moore BR, Benjamin J, Padapu N, Tarongka N, Siba P, et al. Comparison of an assumed versus measured leucocyte count in parasite density calculations in Papua New Guinean children with uncomplicated malaria. Malar J. 2014;13:145.

26. Yetter EM, Acosta KB, Olson MC, Blundell K. Estimating splenic volume: sonographic measurements correlated with helical CT determination. Am J Roentgenol. 2003;181:1615-20.

27. Lamb PM, Lund A, Kanagasabay RR, Martin A, Webb JA, Reznek RH. Spleen size: how well do linear ultrasound measurements correlate with threedimensional CT volume assessments? Br J Radiol. 2002;75:573-7.

28. Lee M, Roberts JM, Chen L, Chang S, Hatala R, Eva KW, et al. Estimation of spleen size with hand-carried ultrasound. J Ultrasound Med. 2014;33:1225-30.

29. Picardi M, Martinelli V, Ciancia R, Soscia E, Morante R, Sodano A, et al. Measurement of spleen volume by ultrasound scanning in patients with thrombocytosis: a prospective study. Blood. 2002;99:4228-30.

30. Eze CU, Odumeru EA, Ochie K, Nwadike UI, Agwuna KK. Sonographic assessment of pregnancy co-existing with uterine leiomyoma in Owerri, Nigeria. Afr Health Sci. 2013;13:453-60.

31. De Odorico I, Spaulding KA, Pretorius DH, Lev-Toaff AS, Bailey TB, Nelson TR. Normal splenic volumes estimated using three-dimensional ultrasonography. J Ultrasound Med. 1999;18:231-6.

32. Watanabe Y, Todani T, Noda T, Yamamoto S. Standard splenic volume in children and young adults measured from CT images. Surg Today. 1997;27:726-8.

33. Yang JC, Rickman LS, Bosser SK. The clinical diagnosis of splenomegaly. West J Med. 1991;155:47-52.

34. Michon P, Cole-Tobian JL, Dabod E, Schoepflin S, Igu J, Susapu MT, et al. The risk of malarial infections and disease in Papua New Guinean children. Am J Trop Med Hyg. 2007;76:997-1008.

35. Laman M, Manning L, Hwaiwhange I, Vince J, Aipit S, Mare T, et al. Lumbar puncture in children from an area of malaria endemicity who present with a febrile seizure. Clin Infect Dis. 2010;51:534-40.

36. Lin E, Tavul L, Michon P, Richards JS, Dabod E, Beeson JG, et al. Minimal association of common red blood cell polymorphisms with Plasmodium falciparum infection and uncomplicated malaria in Papua New Guinean school children. Am J Trop Med Hyg. 2010;83:828-33.

37. Looareesuwan S, Ho M, Wattanagoon Y, White NJ, Warrell DA, Bunnag D, et al. Dynamic alteration in splenic function during acute falciparum malaria. N Engl J Med. 1987;317:675-9.

38. Davis TM, Krishna S, Looareesuwan S, Supanaranond W, Pukrittayakamee S, Attatamsoonthorn $\mathrm{K}$, et al. Erythrocyte sequestration and anemia in severe falciparum malaria. Analysis of acute changes in venous hematocrit using a simple mathematical model. J Clin Invest. 1990;86:793-800.

39. Ndour PA, Lopera-Mesa TM, Diakite SA, Chiang S, Mouri O, Roussel C, et al. Plasmodium falciparum clearance is rapid and pitting independent in 
immune Malian children treated with artesunate for malaria. J Infect Dis. 2015;211:290-7.

40. Morris KP, Naqvi N, Davies P, Smith M, Lee PW. A new formula for blood transfusion volume in the critically ill. Arch Dis Child. 2005;90:724-8.

41. Mollison PL, Hughes Jones NC. Sites of removal of incompatible red cells from the circulation. Vox Sang. 1958;3:243-51.

42. Brown WC, Suarez CE, Shoda LK, Estes DM. Modulation of host immune responses by protozoal DNA. Vet Immunol Immunopathol. 1999:72:87-94.

43. Manning L, Laman M, Davis WA, Davis TM. Clinical features and outcome in children with severe Plasmodium falciparum malaria: a meta-analysis. PLoS One. 2014;9, e86737.

\section{Submit your next manuscript to BioMed Central} and take full advantage of:

- Convenient online submission

- Thorough peer review

- No space constraints or color figure charges

- Immediate publication on acceptance

- Inclusion in PubMed, CAS, Scopus and Google Scholar

- Research which is freely available for redistribution 